\title{
DILATATION OF THE CERVIX BY THE METRANOIKTER OF SCHATZ.
}

By Dr. B. DANIEL ANd DR. R. SCHNEIDER-SIEVERS,

Assistants to Dr. Prochownick's Private Hospital for Women in Hamburg.

THERE is one question which has not failed to gain more and more interest among modern gynæcologists-namely, that an efficacious dilatation of the cavnm uteri is the first condition of the successful diagnosis and treatment of intra-uterine diseases. From time to time, however, doubts arise whether this dilatation is really absolutely necessary in all cases or not. Gessner, for instance, seems to think that a curettage of the uterus would be quite sufficient for both purposes whenever a malignant disease of the endometrium is suspected. Sellheim, too, by no means approves of dilatation of the cervix, even if small portions of the ovum or the membranes are not expelled spontaneously, for he evidently believes it to be always dangerous, to some extent at least, to dilate the uterine cavity so much that one finger can be easily introduced, thus thoroughly examining the interior, especially after abortion or in the puerperium. Macnaughton-Jones says : whenever obscure menorrhagia or metrorrhagia occurs or persists, especially if the discharge continue foul and offensive, there is but one safe rule, which is to dilate and explore the uterus, and not to persevere with palliative treatment. We, in conformity with the majority of gynæcologists, believe that by far the best results are obtained through good dilatation and proper examination of the interior of cervix and body, followed, if necessary, by curettage.

Much has been written and said about this subject, and many attempts made to make the technique of this procedure as simple and perfect as possible. But hitherto no method has been invented, or generally adopted, which really fully suits all the purposes asked for. The ideal method has to be aseptic, efficacious, and comparatively quick, without bringing any danger to the patient.

The first instruments applied were the so-called metrotomes, a kind of bistoury which had to be introduced into the uterus very carefully and well protected, so as to avoid any injuries to the soft parts. By means of this instrument the os internum, the chief obstacle, was cut through. This mode of treatment, however, was neither perfect nor without danger for the patient, because it was 


\section{Daniel and Schneider-Sievers: Dilatation of Cervix $28 \mathrm{I}$}

impossible to work under the control of the eye. Consequently severe bleeding from wounds which had not been seen, or infection through invisible lacerations of the cervix, one had always to be afraid of. Another method has been used by Schroeder. $\mathrm{He}$ dilated the uterine canal through two more or less deep incisions into the portio vaginalis, which generally separated the anterior from the posterior lip in the whole length of the portio, so that the uterus could be put over the finger like the finger of a glove. The same reasons which prevented the first method from attaining much popularity were against Schroeder's, which is now in use in such cases only where a submucous fibroid can be extirpated quickly and easily.

Nowadays, however, those methods are of far greater importance and value by which the cervix can be dilated without involving those manifold dangers which may arise from any wound. The first dilators of this kind were those of Sims, Ellinger, B. S. Schulze, and others. These distend the os internum by means of a pair of branches which are introduced locked, and then spread open. Very often, though, much violence is necessary to open these instruments, and, besides, it is almost impossible to perform this small operation without an anæsthetic. Added to this, lesions of the soft parts easily occur, and the result very often is not quite satisfactory. Hegar's and Fritsch's as well as Jones's dilators are considerably better, as they work slowly, and the effect is produced by degrees. Another advantage is that these instruments can be sterilized without difficulty. On the other hand, however, it is necessary in very many cases to keep the patient under an anæsthetic, the procedure being otherwise rather painful. Besides, it is almost impossible not to make small wounds near the isthmus. In cases of intractable chronic metritis, with a rigid and hard uterus, much time and patience are very often required on the part of the operator, until the task has been accomplished. And it still may not be possible to stretch the muscular tissues of the uterus so much that one finger can be introduced into its cavity. Jakoby, for instance, has published a case where he tried for more than one whole hour to dilate the cervix by means of Hegar's dilators. Nevertheless, the result obtained was far from being satisfactory, so that he was not able to introduce one finger. Vuillet invented another method, which Landau highly recommended as suiting the purpose very well indeed. He employs iodoform gauze instead of instruments, which, of course, has often to be renewed. Again, much time and patience are necessary on the physician's side as well as the patient's, and, what is still worse, it is 
far more difficult with this proceeding to keep up a strict asepsis than with the others, be as careful as you may.

Generally appreciated and in use are the laminaria and tupelo tents, whereas Simpson's sponge tents have been given up everywhere almost, on account of the difficulties in disinfecting them properly before use. 'In this country,' says Macnaughton-Jones, 'three kinds of tents are used-sponge, laminaria, and tupelo-root'; of late years he only uses laminaria. The great advantage of these tents is the likeness of their mechanical effect to that of the physiological contents of the uterus, which is much greater than that of instruments made of glass, or of metal of any kind. The uterine cavity is enlarged and distended gradually, and wounds can be quite easily avoided. This latter point is owing to the fact that the muscularis by degrees gets softer through serous imbibition and a greater affluxion of blood, and consequently can be more easily dilated. These tents, though, have one objection, namely, that sometimes they cannot overcome the resistance of a rigid os internum. It therefore happens now and then that in such cases they do not swell equally well in all parts, remaining thinner in that part where the isthmus surrounded them. Consequently they cannot be extracted save by enlargement of the cervical canal. It also frequently happens that a second, and even a third, has to be employed, oftener in cases of chronic inflammation of the uterus or with uteri of nulliparæ, than with abortions.

So we have seen that all these different methods have their various faults and drawbacks. All the more remarkable is it, therefore, that one method has not been taken more interest in and not been more generally used, which, without pretending to be perfect, enables us to avoid many of the disadvantages of the others. In the last edition of his well-known 'Manual of Diseases of Women,' Macnaughton-Jones says that in previous editions he had figured several specimens of expanding dilators which, however, he believes to be absolutely unnecessary. None of the older editions being at our disposal, we are unable to say whether the instrument we are going to give a few short notes about has been mentioned among them.

In October, I88I, Professor Schatz, of Rostock, showed the Obstetrical Society of Leipzig a new instrument for the purpose of dilating the uterine cavity. Having tried it himself for some length of time before making it generally known, he could say of the same that, being once easily introduced into the uterus, it performed its task gradually, automatically, and in a comparatively short time. 


\section{Daniel and Schneider-Sievers: Dilatation of Cervix $28_{3}$}

Besides, it is exceedingly simple in construction, and is sterilized very easily. In about twelve to twenty-four hours the desired effect is produced, but there is no danger of infection in letting it remain longer. It causes hardly any pain to the patient nor any trouble to the physician, during the time of its installation in the cervix. This instrument is the metranoikter or metroikter of Schatz ( $\mu \eta \tau \eta \rho$,

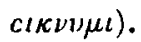

It dilates by means of a strong and round elastic spring, and consists of one part which is to be introduced into the cervix, and a pair of forceps with which it is placed in position. The former, a kind of pin or peg (Fig. I) is $5.5 \mathrm{~cm}$. in length, and $5 \mathrm{~mm}$. thick; it

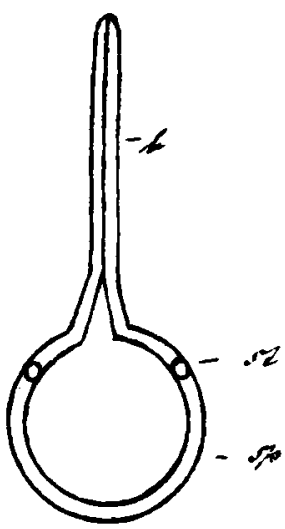

Fig. I,-The InSTRUMENT CLOSED.

$s p$, spring ; $b$, branches ; ss, studs

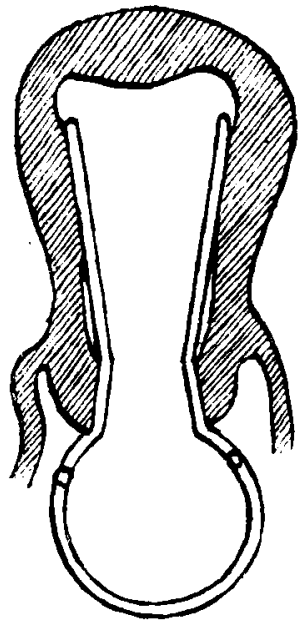

Fig. 2.-The U'TERUS

DILATED BY THE INSTRUMENT.

is slit in the middle, both halves joined together by the spring $(s p)$ mentioned above. When the instrument is open, both branches $(b)$ are about 4 or $5 \mathrm{~cm}$. apart from each other, and the strength which is required to bring them close together-i.e., the resistance of the spring - is the strength of the metroikter. This resistance varies in different sizes from 3 to 8 kilogrammes. This instrument cannot be introduced with the forceps (Fig. 4) unless the two branches are quite close together. Two small studs (ss) on the spring of the dilator fit into a pair of holes $(h)$ in the front part of the forceps. The forceps are applied to these studs, locked and kept in this position by a ring ( $r)$, which is round their handles and movable by pushing it back. Now the instrument is ready for use (Fig. 3). After it is introduced through the os externum, the dilator works 
284 Journal of Obstetrics and Gynæcology

through the elasticity of the spring, which has to separate the two branches again (Fig. 2), and this can only be done through overcoming by degrees the resistance of the muscular tissues of the uterus.

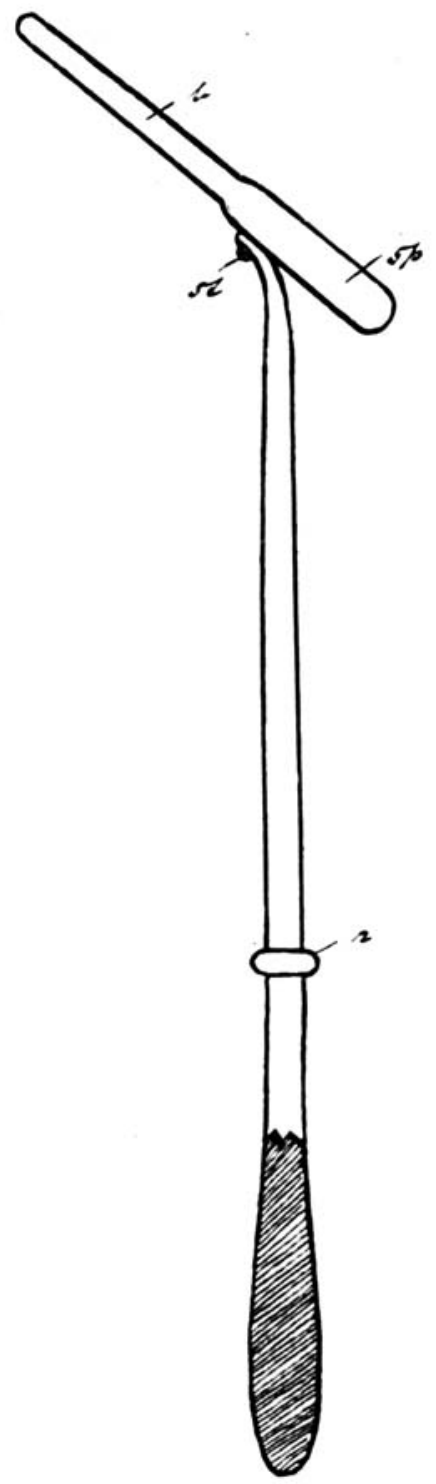

FIG. 3--THE FORCEPS HOLDING THE DILATOR.

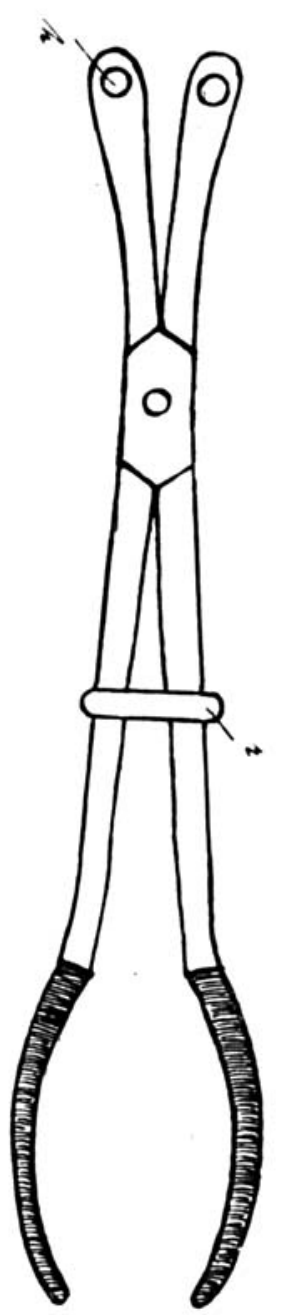

FIG. 4-THE FoRCEPS.

$h$, hole ; $r$, ring.

There are different sizes of these instruments. With very solt uteri it is best to use the smaller ones, of course, the bigger ones with very rigid uteri. In cases of abortions we have generally found Nos. 6 or 7 to be quite sufficiently strong. 


\section{Daniel and Schneider-Sievers: Dilatation of Cervix 285}

After a thorough disinfection of the vagina, and the introduction of the sound in order to make quite sure about the direction of the uterine cavity, the anterior lip of the portio is drawn down with an ordinary pair of tenaculum forceps, and held in this position by an assistant, though this is not absolutely necessary. After these small preparations, the metranoikter is introduced as far as the spring, which has to be lifted over the perinæum, and thus is brought into the vagina. The ring on the handles of the forceps is pushed forward to the lock; the hand of the operator gradually lets the handles go, so that the forceps are opened. They are easily freed from the dilator, and now the spring begins to do its work. To avoid the slipping out of the instrument and any pain which might possibly arise through pressure in the vagina, we generally slightly tamponned the latter, and that is the last act of this small operation, which can very easily be performed without an anæsthetic. The patient is lying either on her side or in the usual dorsal or genu-pectoral position, vulva and vagina being held open either by two fingers of the left hand, or a speculum. Afterwards the patient is put to bed.

As to the literature which we had at hand, it was not possible to find anything mentioned about the 'ikter,' and that is the reason why we suppose it to be hardly known and used at all. Schultze has modified it to some extent. With his instrument the two branches of the dilator are joined to the spring at an angle of $45^{\circ}$; besides, they have cross-headings to prevent the 'ikter' from slipping out of the cervix after its installation. His forceps also are a little handier and lighter.

In our small gynæcological hospital the metranoikter of Schatz was tried and used in $1882-84$. Afterwards this method was abandoned for some time, because in those years the elasticity of the spring could not be got sufficiently durable, and we therefore had to return to the old methods. In 1890 , however, Dr. Hochne, who was then an assistant to our hospital, induced Dr. Prochownick to try it again. He had been in Rostock previously, and at the Frauenklinik there, through several years, had learnt the application of this instrument and the advantages of this method under Schat $z$ himself. Consequently it was applied for a long time in each single case where a dilatation of the uterus was indicated, in order to gain sufficient experience and judgment about its efficacy and usefulness. It has been used in more than roo cases, partly for diagnostic, partly for therapeutic, purposes.

Once only it failed completely, with a nullipara of twenty-six 
years of age. In this case it was absolutely impossible to introduce one finger into the cervix after the inştrument had been removed, because the os internum was so rigid that even the force of the spring had not been able to overcome this rigidity. Three times it was necessary to add a dilatation with the larger sizes of Hegar's dilators (Nos. I 8 to 22), which, however, could be accomplished easily enough without any pains and without an anæsthetic, for the cervical tissues were exceedingly soft and yielding owing to the previous gradual distension through the metranoikter. The same thing had to be done in another case of incarcerated retroflexion of the uterus, where the instrument was found to be lying in the vagina, having slipped out of the cervix. In all the other cases, though, the result proved to be a thoroughly satisfactory one. Twelve to eighteen hours after the installation of the dilator of Schatz one finger could be introduced into the uterine canal without any diffculty, and the cavum could be thoroughly explored or curetted right up to the fundus, or douched and tamponned. This convenient accessibility was especially desirable in cases of polypus or fibroid, or when the diagnosis lay between diseases of either the uterus or the tubes and ovaries. Only once a small wound of the mucous membrane occurred near the os internum, and another time a small depression at the os externum, both, though, without any consequences. Our opinion, therefore, is that this method is not only less dangerous and less inconvenient for the patient, but also much more convenient for the physician or surgeon than any of the others.

Considering the evidently extensive effect of the instrument produced within a couple of hours, one would expect the painfulness of the procedure to be rather great. Such, however, is by no means the case. In the first few hours only, in contrast with the tupelo tents, the patients felt slight pains, and it was seldom necessary to give small doses of morphia or laudanum. Cases (as those described by Jones) with agonizing pain, symptoms of collapse, fainting, etc., 'after the introduction of a single laminaria tent,' we have never seen with our method. It is most likely that the patients have no cause to complain of any bad pains, because the os externum is not filled up totally, as is the case after introduction of laminaria or tupelo. There is plenty of room between the two branches for the secretions of the endometrium to escape.

It may be owing to this same reason that usually the temperature remained at the same height as before. For as we had observed several times that the temperature, after the use of laminaria or tupelo, rose even to $384^{\circ}$ Cels. (102 ${ }^{\circ} \mathrm{Fahr}$.) in the rectum, we paid special 
attention to this point. In three cases only the temperature went up as high as $38 . \mathrm{I}^{\circ} \mathrm{C}$. ( $\mathrm{IOI}^{\circ} \mathrm{F}$.) the day of the introduction of the instrument, always returning to its normal height after the operation the following day; whereas after employment of tents the thermometer sometimes showed a rising tendency, and even the first and second day post operationem $385^{\circ} \mathrm{C}$. (103 ${ }^{\circ} \mathrm{F}$.) could be found pretty often. The application of the metranoikter, therefore, was especially convenient in cases where the cavum uteri had to be dilated quickly, or where there existed besides any inflammatory processes near the uterus or any other infectious diseases. In cases of abortions with previous and still existing moderate fever, the temperature often even returned to its normal height.

Also, as a preparatory means of dilatation the metroikter has proved to be very useful for the vaporization of the uterus as well as for the induction of premature labour. As to the treatment of quite fresh abortions with retention of some portion of the ovum in utero, we had to state one great disadvantage of the instrument. Three times it happened that shortly after it had been introduced hæmorrhage occurred, so that the 'ikter' had to be removed immediately. But, still, even though the time since the installation of the dilator had not been very long, the uterine canal had been enlarged so far that any remaining contents could be scraped away without any difficulties. The hæmorrhage stopped almost immediately.

Its cause in quite recent cases of abortion is not perfectly clear, for generally in such cases where parts of the ovum have remained in the uterus for some time past, or with endometritis deciduæ, fibroids, etc, the introduction of the instrument even seems to stop the bleeding immediately. The reason for this striking fact is that the two branches of the 'ikter' are kept separated from each other through the elasticity of the spring, and that thus the uterine walls are dilated up to the middle of the body, not only during each contraction, but also within the pauses between the pains. The muscular elements, wanting to expel the instrument, contract themselves, and so compress the bleeding vessels.

Summary.-I. The metranoikter of Schatz does not pretend to supersede the other methods of dilatation. But it is not only equal to the older ones, but also superior to them in many cases.

2. The main conditions for which the metroikter proves to be most useful are-

(a) Cases of abortion where portions of the ovum have already been retained for some time.

(b) Hæmorrhage from the uterus in cases where there is no fresh 
abortion, the reason of which has to be found out through digital exploration of the uterine canal, or digital or instrumental denudation of the inside of the uterus.

3. It cannot be recommended in cases of recent abortion, especially with private patients, as these, after the introduction of the instrument, must be kept under constant control. In any such cases, therefore, laminaria or tupelo tents or iodoform gauze must be preferred.

4. It must be recommended and preferred to any other mode of treatment if inflammatory processes take place either in the uterus itself or in its surroundings.

Anyhow, the metranoikter of Schatz deserves to be more tried and appreciated than has hitherto been its lot, and all the more because there are cases also in obstetrics where of late a quick dilatation of the cervix by means of instruments (Bossi, Leopold) is considered to be advisable. It therefore does seem very likely to us that also in these-eclampsia, for instance-our method, after the instrument has perhaps been altered to suit its new purpose, may prove to be of great value to the obstetrician.

Our thanks are due to Geheimrat Schatz for his kind permission to reproduce some of the illustrations given in his first paper on this subject. As we are informed, he is about to publish some notes about the manufacturing of and testing the metranoikter in the Archiv für Gynäkologie.

\section{LITERATURE.}

I Gessner: 'Bemerkungen zu Saenger's Vortrag,' etc., Centralbl. f. Gy'n., 1898 , No. 12.

' JAKоBY: 'Über Dilatation des Uterus. Howitz,' Gyn. og Obst. Meddel., vol. iv., I, 2.

3 LEOPOLD : 'Über die schnelle Erweiterung des Muttermundes mittelst des Dilatatoriums von Bossi,'Arch.f. Gyn, vol. 1xvi., 'T.

4 Ibid: : 'Zur schnellen vollständigen Erweiterung des Muttermundes mittelst des Dilatators von Bossi, namentlich bei Eklampsie, Centralbl. f. Gyn., I902, No. I9.

5 Macnaughton-Jones: 'Practical Manual of Diseases of Women and Uterine Therapeutics,' ed. I900.

${ }^{6}$ SCHATZ: 'Ein neues Instrument zur ergiebigen Eröfnung des Uterus. Metranoikter,' Arch.f. Gyn., vol. xviii.

7 SCHUltze : 'Irrigationskatheter für den Uterus und modificierter Metranoikter,' Ill. Monatschr. der äratl, Polytechnik, I883, iii.

8 Sellheim : 'Principien und Gefahren der Abortbehandlung,' Mïnchn. Med. Wochenschr., 1902, No. ro.

9 Sussdorf : Med. Record, New York, i877.

ro TAIT: Obst. Journ. of Great Britain and Ireland, 1879, September I8, p. 379 .

Manufacturers of the instrument are Moessinger jun., Instrument-maker, Rostock, and Moecke, Leipzig. 